\title{
Body composition and performance variables differences in female volleyball players by age- group and playing position
}

\section{Diferenças na composição corporal e variáveis de desempenho em atletas femininas de voleibol por faixa etária e posição de jogo}

\author{
Lucas Samuel Tessutti \\ (D) https://orcid.org/0000-0001-6118-2096 \\ Samuel da Silva Aguiar ${ }^{2}$ \\ (D) https://orcid org/0000-0002-9057-4096 \\ Gustavo De Conti Teixeira Costa ${ }^{3}$ \\ (D) https://orcid.org/0000-0003-0911-8753 \\ Filipe Manuel Clemente ${ }^{4}$ \\ (1) https://orcid.org/0000-0001-9813-2842 \\ Ricardo Franco Lima ${ }^{4}$ \\ (D) https://orcid.org/0000-0003-3552-7534 \\ Rodrigo Vanerson Passos Neves ${ }^{5}$ \\ (D) https://orcid.org/0000-0002-3257-7870 \\ Gibson Moreira Praça ${ }^{6}$ \\ (D) https://orcid.org/0000-0001-9971-7308 \\ Henrique de Oliveira Castro \\ (D) https://orcid.org/0000-0002-0545-164X
}

Abstract - The aim of the present study was to evaluate the age and inter- and intra-position differences in the anthropometric variables and physical performance in young female players of Brazilian women's volleyball. Fifty-eight female volleyball players participated, divided into 3 age groups: (a) 14 and under ( $n=20$; mean age $=12.6 \pm 0.7$ years), (b) between 14 and $17(\mathrm{n}=31$; mean age $=15.6 \pm 1.2$ years $)$, and $(\mathrm{c})$ over $17(\mathrm{n}=7$; mean age $=18.9 \pm 0.9$ years $)$. In addition, the players were also divided according to their positions: setters $(n=7)$, opposites $(n=13)$, passer-hitters $(n=17)$, middle blockers $(n=12)$ and liberos $(n=9)$. Anthropometric characteristics, flexibility, strength / resistance abdominal muscles, pushups, explosive power of the arms, jumping abilities, shuttle run and 20-m sprint tests were evaluated. Analyses showed differences among age and playing positions for the height and bone mass $(p<0.05)$. In the fitness assessment, no differences were found between playing positions $(p>0.05)$. However, differences were found among for age groups horizontal jump, shuttle run and $20-\mathrm{m}$ sprint, with players $>17$ performing better than $<14$ and between $14-17$ years of age $(p<0.05)$. These results demonstrated that the height, bone mass and horizontal jump, shuttle run and $20-\mathrm{m}$ sprint are age dependent, while physical performance independent on the playing positions.

Key words: Anthropometric measures; Athlete; Physical characteristics, Volleyball.

Resumo - Objetiva-se avaliar a idade e as diferenças inter e intra-posiçôes nas variáveis antropométricas e no desempenho físico de jovens jogadoras do voleibol feminino brasileiro. Participaram 58 atletas femininas de voleibol, divididas em 3 grupos por faixa etária: (a) até 14 ( $n=20$; idade média =12,6 0,7 anos), (b) entre 14 e 17 ( $n=31$; média de idade =15,6 $\pm 1,2$ anos); (c) acima de 17 ( $n=7$; idade média $=18,9 \pm 0,9$ anos). Além disso, os jogadores também foram divididos de acordo com suas posiçôes: levantadores $(n=7)$, opostos $(n=13)$, passadores $(n=17)$, bloqueadores $(n=12)$ e líberos. $(n=9)$. Foram avaliadas as características antropométricas, flexibilidade, força I resistência dos músculos abdominais, flexões, poder explosivo dos braços, habilidades de salto, corrida e corrida de $20 \mathrm{~m}$. As análises mostraram diferenças entre idade e posiçôes de jogo para a altura e massa óssea $(p<0,05)$. Na avaliação da aptidão, não foram encontradas diferenças entre as posiçôes de jogo ( $p>0,05)$. No entanto, foram encontradas diferenças entre os grupos etários: salto horizontal, corrida e corrida de $20 \mathrm{~m}$, com os jogadores acima de 17, com desempenho melhor que menores que 14 e entre 14 e 17 anos de idade $(p<0,05)$. Estes resultados demonstraram que a altura, a massa óssea e o salto horizontal, o deslocamento e a velocidade de $20 \mathrm{~m}$ são dependentes da idade, enquanto que 0 desempenho físico é independente das posiçôes de jogo.

Palavras-chave: Atletas; Características físicas; Medidas antropométricas; Voleibol.
1 Centro Universitário Estácio de Brasília. Taguatinga, DF. Brazil.

2 Centro Universitário do Distrito Federal. Brasília, DF. Brazil.

3 Universidade Federal de Goiás. Goiânia, GO. Brazil.

4 School of Sport and Leisure. Polytechnic Institute of Viana do Castelo. Portugal.

5 Universidade Católica de Brasília. Taguatinga, DF. Brazil.

6 Universidade Federal de Minas Gerais. Belo Horizonte, MG. Brazil.

Received: 09 November 2018 Accepted: 20 July 2019

How to cite this article Tessutti LS, Aguiar SS, Costa GDC, Clemente FM, Lima RF, Neves RVP, Praça GM, Castro HO. Body composition and performance variables differences in female volleyball players by agegroup and playing position.Rev Bras Cineantropom Desempenho Hum 2019, 21:e60131.D0I: http://dx.doi. org/10.1590/1980-0037.2019v21e60131

Copyright: This work is licensed under a Creative Commons Attribution 4.0 International License. 


\section{INTRODUCTION}

In Volleyball, despite required a high level of physical fitness ${ }^{1}$, the athletic performance depends on a combination of technical, tactical, physical, psychological and anthropometric characteristics. When compared boys and girls characteristic, there are differences between body height, weight, body mass index, jump height and team level ${ }^{2}$. Thus, ectomorph somatotype as height, low percentage of values of body fat weight, and low values of triceps skinfolds, calf and abdomen are identified as the anthropometric measures in men's volleyball elite athletes ${ }^{3,4}$.

Furthermore, in female volleyball players, the higher performance level, more appropriate values of body composition parameters ${ }^{1}$, that is why studies reveal that the physical fitness can influence the technical performance of the athletes 5 .

With body composition differences between genres and ages, the coach should give special training consideration to ectomorph centers ${ }^{6}$ and agespecific positional differences, because performance in female volleyball players are dependent of age and morphologic structure and playing posi$\operatorname{tion}^{7,8}$. Research indicate middle blockers are tallers, more ectomorphic, less mesomorphic and endomorphic. Besides that, more successful players in all positions had a lower body mass index, were less mesomorphic and endomorphic, and more ectomorphic than less successful players".

Thus, the study of anthropometric characteristics in relation to playing position, performance and age is very important to coaches, to guide and plan the physical condition of their athlete's and the ability to make tailored position-specific training programs among different ages ${ }^{7,8}$. Furthermore, the information about anthropometric characteristics of the players orient the coach in team management ${ }^{2}$.

This study included a comparison of the anthropometric characteristics of the players, and despite of the importance of that, there is no consensus in the literature on the main characteristics to be evaluated. Thus, it is necessary to understand the main characteristic to have better performance in volleyball. The aim of the present study was to analyze age and inter and intra-positional differences in anthropometric and physical performance variables (lower limb power, upper body power, agility, speed and flexibility) of young female volleyball players in Brazil.

\section{METHOD}

The study followed the ethical recommendations of Declaration of Helsinki for the study in humans. Furthermore, all the subjects completed an informed consent form before participation.

The parents of the players who were under the age of 18 years approved the participation of their children in the study. Additionally, the present study was conducted with the full accordance of volleyball club. The exclusion criteria adopted in the current study was: (a) potential medical 
problems or a history of ankle, knee, or back pathology that compromised their participation in the proposed performance tests; (b) any lower extremity reconstructive surgery in the past 2 years.

The participants were underwent a series of anthropometric and physical performance measurements conducted in indoor volleyball gyms between 2:00 and 8:00 PM, respecting the hours of training of the athletes.

\section{Subjects}

Fifty-eight female volleyball players participated in this study. They were divided into 3 age groups: (a) 14 and under $(n=20$; mean age $=12.6 \pm 0.7$ years), (b) between 14 and $17(\mathrm{n}=31$; mean age $=15.6 \pm 1.2$ years $)$, and (c) over $17(\mathrm{n}=7$; mean age $=18.9 \pm 0.9$ years). In addition, the players were also divided into 5 groups according to their positions for analysis: setters $(n=7)$, opposites $(n=13)$, passer-hitters $(n=17)$, middle blockers $(n=12)$ and liberos $(n=9)$.

All players, compete in highest level in regional and national tournaments. Volleyball experience of the players ranged from 1.0 to 8.0 years, with a mean of $3.7 \pm 1.8$ years, and weekly training duration ranged from 240 to $900 \mathrm{~min}^{*} \mathrm{wk}^{-1}$, averaging $513.1 \pm 261.9 \mathrm{~min} \cdot \mathrm{wk}^{-1}$.

\section{Procedures}

The participants were provided with a verbal explanation of the experimental design of the study. All testing was conducted by an experienced exercise physiologist (with experience in research projects in exercise physiology) and the testing order was same in all groups: anthropometric characteristics were measured first, followed by measurement of performance physical.

The players performed all tests twice and the higher value recorded in each test was used in the analysis. During all tests, verbal encouragement was provided to assure that players reached the best performance possible. Testing lasted about 25-30 minutes for each player. All subjects were given a standardized warm-up, which included 10 minutes of drill exercise and 5 minutes of static and dynamic stretching.

\section{Anthropometric characteristics}

Body mass and height were measured using an electronic weight scale with stadiometer (Welmy ${ }^{\circledR}$, Brazil), with an accuracy of $0.1 \mathrm{~kg}$ and $0.1 \mathrm{~cm}$, respectively. Body Mass Index (BMI) was calculated as body mass divided by stature squared and expressed as $\mathrm{kg} \cdot \mathrm{m}^{-2}$. Relative body fat was estimated using the seven-fold protocol as previously described to the International Society for the Advancement of Kinanthropometry - ISAK ${ }^{10}$. A single evaluator collected all measurements using a compass of skinfolds (Sanny ${ }^{\circledR}$, Brazil) with an accuracy of $0.1 \mathrm{~mm}$. Body circumferences (waist and hip) were measured using a measuring tape (Sanny ${ }^{\circledR}$, Brazil). The epicondylar amplitude of the humerus and femur and bi-styloid wrist process were measured with pachymeter $\left(\right.$ Sanny ${ }^{\circledR}$, Brazil) with an accuracy of $0.1 \mathrm{~mm}$. Somatotype was assessed as proposed by Heath and $\mathrm{Carter}^{11}$. 


\section{Performance measurements}

Flexibility- Sit-and-reach test: The sit-and-reach test protoco ${ }^{12}$ was employed for the assessment of low back and hamstring flexibility. An advantage of $15 \mathrm{~cm}$ was set at the position of just reaching the toes. Three trials were performed, with 30 seconds rest between them. The best score in $\mathrm{cm}$ was recorded.

- Abdominals: The strength / resistance of the abdominal muscle was evaluated from the trunk flexion test, in which the adolescents should perform the greatest number of repetitions of the abdominal exercise during a period of 60 seconds.

- Pushups: Upper body strength and endurance were assessed by performance on the $90^{\circ}$ pushups test during a period of 60 seconds. The maximal number was recorded.

- Medicine ball throw: A 2-kg medicine ball throw for assessing explosive power of the arms was performed from a supine position (i.e., the subject was asked subject to throw the ball forward from a supine position as far as possible) with the result expressed in meters. Three trials were performed, with 1 minute rest between them. The best score in $\mathrm{cm}$ was recorded.

- Jumping abilities: Vertical jump (simulating spike and block fundamentals) and horizontal jump were performed to assess muscle power. During vertical jump, each subject had her right fingertips marked with orange chalk. She stood with a wall at her right side, reached up as high as possible with her right hand, and marked the wall while keeping her left arm down and feet flat on the floor. She then assumed a bent-knees preparatory position, paused, and jumped as high as possible, touching the wall again with her fingers. The vertical jump simulating a spike (VJS) was used only the extension of the dominant arm, whereas, the vertical jump simulating a block (VJB) was used the extension of the two arms. To perform the horizontal jump, subjects stood on the designated testing leg with their toe in front of the starting line, and their hands on their hips. Subjects were instructed to sink (approximately $120^{\circ} \mathrm{knee}$ angle) as quickly as possible and then jump as far forward as possible and land on two feet. Three trials were performed, with 1 minute rest between them. The best score in $\mathrm{cm}$ was recorded.

- Shuttle run test: The shuttle run test was changed from yards to meters, creating a $4 \times 9.14 \mathrm{~m}$ course. On the "go" command, the participant ran forward as quickly as possible to the second cone and turned back to the first cone, repeating this procedure 4 times. The stop watch was used to take the subjects' time to then rest $0.01 \mathrm{~s}$ (Germany, $-0.04 \pm 0.24 \mathrm{~s}$ ).

- 20-m sprint: Speed was determined by a timed 20-m sprint. Timing began at the subject's movement out of a 2-point (base-running) stance. Sprint times were determined using a speed digital handheld stopwatch (Germany, $-0.04 \pm 0.24 \mathrm{~s}$ ). Three trials were performed, with 1 minute rest between them. The best score in $\mathrm{cm}$ was recorded. 


\section{Statistical Analysis}

MANOVA tested the interactions between age groups and playing positions. After that, comparisons between age groups and playing positions were made by using one-way ANOVA test. The partial eta squared $\left(\eta_{p}^{2}\right)$ has tested the effect size of ANOVA (ES). The Ferguson's classification for the ES was used: no effect $(\mathrm{ES}<0.04)$; minimum effect $(0.04<\mathrm{ES}<$ $0.25)$; moderate effect $(0.25<\mathrm{ES}<0.64)$; and strong effect $(\mathrm{ES}>0.64)$. The pair wise comparisons were tested with Cohen's $d$ to analyze the effect size. The following classification to measure the magnitude of $\mathrm{ES}$ was used: no effect $(d<0.41)$, minimum effect $(0.41<d<1.15)$, moderate effect $(1.15$ $<d<2.70)$ and strong effect $(d>2.70)$. All statistical analysis was carried out using SPSS statistical analysis software (SPSS version 23.0, Chicago, USA). The level of statistical significance was set at $p \leq 0.05$.

\section{RESULTS}

\section{Anthropometrics and body composition}

Descriptive statistics (mean $\pm 90 \%$ confidence intervals) of the anthropometrics and body composition characteristics of under-14, 14-17 and over-17 groups are presented in Table 1 . Significant interaction between age and playing position were found in bone mass $\left(p=0.001 ; \eta_{p}^{2}=1.000\right.$; perfect effect).

No significant interactions between age and playing positions were found in body mass $\left(p=0.161 ; \eta_{p}^{2}=0.203\right.$; minimum effect $)$, height $(p=$ $0.236 ; \eta_{p}^{2}=0.181$; minimum effect $), \mathrm{BMI}\left(p=0.470 ; \eta_{p}^{2}=0.133\right.$; minimum effect), body fat $\left(p=0.190 ; \eta_{p}^{2}=0.194\right.$; minimum effect $)$, waist circumference $\left(p=0.585 ; \eta_{p}^{2}=0.114 ;\right.$ minimum effect $)$, hip circumference $\left(p=0.267 ; \eta_{p}^{2}=\right.$ 0.173 ; minimum effect $)$, endomorphy $\left(p=0.167 ; \eta_{p}^{2}=0.201\right.$; minimum effect $)$, mesomorphy $\left(p=0.333 ; \eta_{p}^{2}=0.139\right.$; minimum effect $)$ and ectomorphy $(p=$ $0.246 ; \eta_{p}^{2}=0.178$; minimum effect $)$.

Significant differences between age groups were found in height $(p=$ $0.025 ; \eta^{2}=0.125$, minimum effect $)$ and hip circumference $\left(p=0.003 ; \eta^{2}\right.$

Table 1. Mean [ $90 \%$ confidence intervals] of body mass, height, BMI, body fat, bone mass, waist circumference, hip circumference, endomorphy, mesomorphy and ectormorphy.

\begin{tabular}{lcccc}
\hline & \multicolumn{1}{c}{$<$ yo } & $14-17$ yo & $>17$ yo & $\boldsymbol{p}\left|\boldsymbol{\eta}_{p}^{2} \boldsymbol{\eta}_{p}^{2}\right|$ effect \\
\hline Body mass (Kg) & $61.41[56.48 ; 66.34]$ & $65.88[63.2 ; 68.56]$ & $61.43[52.91 ; 69.96]$ & $0.161|0.203|$ minimum \\
Height (cm) & $167.45[164.79 ; 170.11]$ & $173.45[171.27 ; 175.63]$ & $169.5[162.31 ; 176.69]$ & $0.236|0.181|$ minimum \\
BMI $\left(\mathrm{Kg} / \mathrm{m}^{2}\right)$ & $21.8[20.35 ; 23.25]$ & $21.9[21.1 ; 22.7]$ & $21.23[19.29 ; 23.17]$ & $0.470|0.133|$ minimum \\
Body fat (\%) & $27.95[25.84 ; 30.05]$ & $25.85[24.39 ; 27.30]$ & $23.35[19.89 ; 26.81]$ & $0.190|0.194|$ minimum \\
Bone mass (Kg) & $11.9[10.71 ; 13.09]$ & $12.78[12.09 ; 13.47]$ & $11.40[9.31 ; 13.49]$ & $0.001|1.000|$ perfect \\
Waist Circumference (cm) & $75.46[71.92 ; 78.99]$ & $77.36[75.21 ; 79.52]$ & $74.17[69.44 ; 78.89]$ & $0.585|0.114|$ minimum \\
Hip Circumference (cm) & $87.69[83.43 ; 91.95]$ & $95.92[93.54 ; 98.30]$ & $96.25[91.14 ; 101.36]$ & $0.267|0.173|$ minimum \\
Endomorphy & $6.38[5.50 ; 7.25]$ & $5.79[5.28 ; 6.30]$ & $6.55[5.45 ; 7.65]$ & $0.167|0.201|$ minimum \\
Mesomorphy & $8.38[8.02 ; 8.73]$ & $8.67[8.47 ; 8.88]$ & $8.20[7.60 ; 8.80]$ & $0.333|0.139|$ minimum \\
Ectomorphy & $8.48[7.90 ; 9.06]$ & $8.00[7.73 ; 8.27]$ & $8.47[7.33 ; 9.60]$ & $0.246|0.178|$ minimum \\
\hline
\end{tabular}

Note. yo - years old. 
$=0.186$, minimum effect $)$. The 14-17 group was taller than $<14$ group $(d=$ 0.852 , minimum effect $)$ and $>17$ group $(d=0.591$, minimum effect $)$.

Greater values of bone mass were found in $>17$ group than in $<14$ group $(d=1.054$, minimum effect $)$ and $14-17(d=0.360$, no effect $)$. No significant differences between age groups were found in body mass $\left(p=0.357 ; \eta^{2}=\right.$ 0.037 , no effect $)$, BMI $\left(p=0.989 ; \eta^{2}=0.001\right.$, no effect $)$, body fat $(p=0.153$; $\eta^{2}=0.066$, minimum effect $)$, bone mass $\left(p=0.332 ; \eta^{2}=0.040\right.$, no effect $)$, waist circumference $\left(p=0.687 ; \eta^{2}=0.014\right.$, no effect $)$, endomorphy $(p=$ $0.383 ; \eta^{2}=0.034$, no effect $)$, mesomorphy $\left(p=0.239 ; \eta^{2}=0.052\right.$, minimum effect $)$ and ectomorphy $\left(p=0.387 ; \eta^{2}=0.034\right.$, no effect $)$.

Comparison of anthropometrics and body composition between playing position was made by using one-way ANOVA test and eta squared. Descriptive statistics and statistical results can be found in table 2 .

Considering the variances detected in the variables, libero was smaller than opposites $(d=1.232$, moderate effect $)$, passer-hitters $(d=1.495$, moderate effect $)$ and middle blockers $(d=1.786$, moderate effect $)$. Regarding the bone mass, the libero had significant smaller values than opposites $(d=$ 1.170 , moderate effect $)$, setters $(d=0.680$, minimum effect $)$, PAS $(d=1.662$, moderate effect $)$ and middle blockers $(d=1.333$, moderate effect $)$.

\section{Fitness Assessment}

Descriptive statistics (mean $\pm 90 \%$ confidence intervals) of the fitness characteristics of under-14, 14-17 and over-17 groups are presented in Table 3.

No significant interactions between age and playing positions were found in number of abdominals $\left(p=0.966 ; \eta_{p}^{2}=0.040\right.$; no effect $)$, number of pushups $\left(p=0.092 ; \eta_{p}^{2}=0.237\right.$; minimum effect $)$, medicine ball throw $\left(p=0.152 ; \eta_{p}^{2}=0.206 ;\right.$ minimum effect $)$, horizontal jump $\left(p=0.214 ; \eta_{p}^{2}\right.$ $\eta_{p}^{2}=0.190 ;$ minimum effect $)$, VJS $\left(p=0.095 ; \eta_{p}^{2}=0.235\right.$; minimum effect $)$, $\operatorname{VJB}\left(p=0.213 ; \eta_{p}^{2}=0.190 ;\right.$ minimum effect $)$, shuttle run $\left(p=0.597 ; \eta_{p}^{2}=\right.$ 0.112 ; minimum effect $), 20-\mathrm{m}$ sprint $\left(p=0.557 ; \eta_{p}^{2}=0.118\right.$; minimum effect $)$ and flexibility $\left(p=0.832 ; \eta_{p}^{2}=0.073\right.$; minimum effect $)$.

Significant differences between age groups were found in horizontal

Table 2. Mean \pm standard deviation of anthropometrics and body composition characteristics of players between playing positions

\begin{tabular}{lllllll}
\hline & Opo $(n=13)$ & Set $(n=7)$ & Lib $(n=9)$ & Pas $(n=17)$ & Mid $(n=12)$ & $p\left|\eta^{2}\right|$ effect \\
\hline Body mass $(\mathrm{Kg})$ & $67.36_{ \pm} 10.96$ & $63.29_{ \pm} 14.63$ & $58.41_{ \pm} 8.32$ & $63.59_{ \pm} 7.11$ & $66.81_{ \pm} 14.10$ & $0.362|0.077|$ minimum \\
Height $(\mathrm{cm})$ & $172.31_{ \pm} 7.73$ & $168.71_{ \pm} 8.71$ & $163.22_{ \pm} 6.82$ & $172.53_{ \pm} 5.91$ & $175.67_{ \pm} 7.08$ & $0.003|0.254|$ moderate \\
BMI $\left(\mathrm{Kg} / \mathrm{m}^{2}\right)$ & $22.58_{ \pm} 2.35$ & $22.00_{ \pm} 3.60$ & $21.96_{ \pm} 3.32$ & $21.44_{ \pm} 2.96$ & $21.48_{ \pm} 3.41$ & $0.871|0.023|$ no effect \\
Body fat $(\%)$ & $28.15_{ \pm} 5.37$ & $25.71_{ \pm} 4.95$ & $26.23_{ \pm} 5.41$ & $25.45_{ \pm} 4.11$ & $26.36_{ \pm} 5.97$ & $0.690|0.041|$ minimum \\
Bone mass $(\mathrm{Kg})$ & $13.48_{ \pm} 3.42$ & $11.63_{ \pm} 2.73$ & $10.14_{ \pm} 1.68$ & $12.23_{ \pm} 0.98$ & $13.35_{ \pm} 2.86$ & $0.020|0.198|$ minimum \\
Waist Circum- & $77.33_{ \pm} 8.05$ & $77.19_{ \pm} 8.90$ & $75.33_{ \pm} 4.69$ & $75.75_{ \pm} 6.61$ & $77.33_{ \pm} 10.73$ & $0.955|0.012|$ no effect \\
ference $(\mathrm{cm})$ & & & & & \\
Hip Circumfer- & $94.19_{ \pm} 11.59$ & $91.09_{ \pm} 14.64$ & $91.06_{ \pm} 6.50$ & $92.89_{ \pm} 6.47$ & $96.51_{ \pm} 11.80$ & $0.718|0.038|$ no effect \\
ence (cm) & & & & & \\
Endomorphy & $6.55_{ \pm} 2.08$ & $5.90_{ \pm} 1.33$ & $6.53_{ \pm} 2.15$ & $5.76_{ \pm} 1.60$ & $5.87_{ \pm} 2.13$ & $0.734|0.037|$ no effect \\
Mesomorphy & $8.85_{ \pm} 0.99$ & $8.53_{ \pm} 0.85$ & $8.21_{ \pm} 0.63$ & $8.39_{ \pm} 0.46$ & $8.58_{ \pm} 0.95$ & $0.388|0.075|$ minimum \\
Ectomorphy & $7.80_{ \pm} 0.91$ & $8.34_{ \pm} 1.68$ & $8.56_{ \pm} 1.31$ & $8.23_{ \pm} 0.95$ & $8.19_{ \pm} 1.20$ & $0.690|0.041|$ minimum \\
\hline
\end{tabular}

Note. Opo - opposite hitter; Set - setter; Lib - libero; Pas - passer-hitter; Mid - midlle blocker. 
jump ( $p=0.001 ; \eta^{2}=0.271$, moderate effect $)$, VJS $\left(p=0.002 ; \eta^{2}=0.200\right.$, minimum effect $)$, shuttle run $\left(p=0.001 ; \eta^{2}=0.430\right.$, moderate effect $)$ and 20 - m sprint $\left(p=0.001 ; \eta^{2}=0.266\right.$, moderate effect $)$.

Pairwise comparison revealed that $>17$ group jumped longer than $>14$ group $(d=1.961$, moderate effect $)$ and $14-17(d=1.178$, moderate effect $)$. The $>17$ group also jumped higher (VJS) than $<14$ group $(d=1.489$, moderate effect) and 14-17 group ( $d=0.725$, minimum effect $)$. Considering the shuttle run, < 14 group ran longer than 14-16 ( $d=0.976$, minimum effect $)$ and $>17$ group $(d=3.725$, large effect $)$. Finally, $>17$ group ran faster in $20-\mathrm{m}$ sprint than $<14$ group $(d=2.293$, moderate effect $)$ and 14-17 group $(d=0.939$, minimum effect).

No significant differences between age groups were found in number of abdominals $\left(p=0.240 ; \eta^{2}=0.051\right.$, minimum effect $)$, number of pushups $\left(p=0.801 ; \eta^{2}=0.008\right.$, no effect $)$, medicine ball throw $\left(p=0.096 ; \eta^{2}=\right.$ 0.082 , minimum effect $)$, VJB $\left(p=0.092 ; \eta^{2}=0.085\right.$, minimum effect $)$ and flexibility $\left(p=0.488 ; \eta^{2}=0.026\right.$, no effect $)$.

Comparison of fitness characteristics between playing position was made by using one-way ANOVA test and eta squared. Descriptive statistics and statistical results can be found in table 4 .

Table 3. Mean [90\% confidence intervals] of abdominals, pushups, medicine ball throw, horizontal jump, VJS, VJB, shuttle run, 20-m sprint and flexibility.VJS - vertical jump simulating spike; VJB - vertical jump simulating block; Flexibility - Sit-and-reach test; 20-m sprint - 20-meters sprint.

\begin{tabular}{lcccc}
\hline & $<14$ yo & $14-17$ yo & $>17$ yo & $\boldsymbol{p}\left|\boldsymbol{\eta}_{\mu}^{2} \boldsymbol{\eta}_{p}^{2}\right|$ effect \\
\hline Abdominals (n) & $35.68[31.47 ; 39.89]$ & $40.86[37.69 ; 44.04]$ & $37.57[34.52 ; 40.63]$ & $0.966|0.040|$ no effect \\
Pushups (n) & $35.58[32.35 ; 38.81]$ & $37.83[34.58 ; 41.08]$ & $37.57[28.67 ; 46.47]$ & $0.092|0.237|$ minimum \\
Medicine ball throw (m) & $3.27[3.08 ; 3.46]$ & $3.48[3.37 ; 3.60]$ & $3.67[3.19 ; 4.15]$ & $0.152|0.206|$ minimum \\
Horizontal jump (m) & $1.58[1.49 ; 1.67]$ & $1.73[1.66 ; 1.80]$ & $1.98[1.86 ; 2.10]$ & $0.214|0.190|$ minimum \\
VJS (cm) & $39.53[36.55 ; 42.51]$ & $45.17[42.94 ; 47.40]$ & $50.14[45.81 ; 54.48]$ & $0.095|0.235|$ minimum \\
VJB (cm) & $31.00[28.31 ; 33.69]$ & $32.76[30.97 ; 34.55]$ & $36.86[33.62 ; 40.10]$ & $0.213|0.190|$ minimum \\
Shuttle run (sec) & $12.65[12.36 ; 12.95]$ & $11.72[11.38 ; 12.05]$ & $10.20[9.92 ; 10.49]$ & $0.597|0.112|$ minimum \\
20-m sprint (sec) & $4.33[4.24 ; 4.43]$ & $4.08[3.97 ; 4.20]$ & $3.76[3.55 ; 3.97]$ & $0.557|0.118|$ minimum \\
Flexibility (cm) & $31.42[28.47 ; 34.37]$ & $32.72[30.40 ; 35.05]$ & $32.86[29.03 ; 36.68]$ & $0.832|0.073|$ minimum \\
\hline
\end{tabular}

Note. yo - years old.

Table 4. Mean \pm standard deviation of fitness characteristics of players between playing positions

\begin{tabular}{lllllll}
\hline & Opo $(\mathrm{n}=13)$ & Set $(\mathrm{n}=7)$ & Lib $(\mathrm{n}=9)$ & Pas $(\mathrm{n}=17)$ & Mid $(\mathrm{n}=12)$ & $p\left|\eta^{2}\right|$ effect \\
\hline Abdominals $(\mathrm{n})$ & $39.54_{ \pm} 13.35$ & $36.86_{ \pm} 5.64$ & $41.00_{ \pm} 10.58$ & $37.12_{ \pm} 8.43$ & $38.42_{ \pm} 8.83$ & $0.871|0.023|$ no effect \\
Pushups $(\mathrm{n})$ & $38.69_{ \pm} 10.04$ & $35.86_{ \pm} 4.45$ & $37.56_{ \pm} 7.81$ & $36.44_{ \pm} 12.86$ & $37.42_{ \pm} 9.63$ & $0.970|0.010|$ no effect \\
Medicine ball throw $(\mathrm{m})$ & $3.35_{ \pm} 0.44$ & $3.32_{ \pm} 0.70$ & $3.28_{ \pm} 0.42$ & $3.68_{ \pm} 0.40$ & $3.35_{ \pm} 0.32$ & $0.124|0.126|$ minimum \\
Horizontal jump (m) & $1.64_{ \pm} 0.21$ & $1.64_{ \pm} 0.32$ & $1.71_{ \pm} 0.15$ & $1.73_{ \pm} 0.30$ & $1.76_{ \pm} 0.19$ & $0.745|0.036|$ no effect \\
VJS (cm) & $40.77_{ \pm} 7.64$ & $42.86_{ \pm} 10.73$ & $45.33_{ \pm} 3.84$ & $45.35_{ \pm} 9.13$ & $44.73_{ \pm} 6.12$ & $0.533|0.058|$ minimum \\
VJB (cm) & $31.69_{ \pm} 6.17$ & $31.71_{ \pm} 4.86$ & $35.89_{ \pm} 2.37$ & $31.89_{ \pm} 8.11$ & $32.45_{ \pm} 5.03$ & $0.489|0.063|$ minimum \\
Shuttle run $(\mathrm{sec})$ & $12.00_{ \pm} 1.12$ & $11.94_{ \pm} 1.34$ & $11.71_{ \pm} 1.26$ & $11.82_{ \pm} 1.31$ & $11.96_{ \pm} 0.92$ & $0.980|0.008|$ no effect \\
20-m sprint $(\mathrm{sec})$ & $4.20_{ \pm} 0.38$ & $4.19_{ \pm} 0.34$ & $3.94_{ \pm} 0.36$ & $4.09_{ \pm} 0.34$ & $4.21_{ \pm} 0.35$ & $0.397|0.073|$ no effect \\
Flexibility (cm) & $31.31_{ \pm} 6.54$ & $31.14_{ \pm} 5.49$ & $34.44_{ \pm} 10.24$ & $34.00_{ \pm} 5.93$ & $29.58_{ \pm} 8.43$ & $0.456|0.065|$ minimum \\
\hline
\end{tabular}

Note Opo - opposite hitter; Set - setter; Lib - libero; Pas - passer-hitter; Mid - midlle blocker. 


\section{DISCUSSION}

This study investigated the anthropometric and physical performance attributes of elite young female volleyball athletes and determined if differences exist in these characteristics according to age and playing position.

Analyses showed significant differences among age and playing positions for the height and bone mass. In the fitness assessment, no differences were found between playing positions. However, differences were found among for age groups horizontal jump, shuttle run and 20-m sprint, with players $>17$ performing better than $<14$ and between $14-17$ years of age.

These data do not agree with previous studies that observed differences in performance parameters between game positions in a wide range of sports $^{13-15}$. Furthermore, it seems that the anthropometric characteristics are age dependent, whereas physical performance seems to be dependent on the playing positions ${ }^{8}$.

Usually, the selection of young female volleyball players for specific playing positions in the analyzed clubs are mostly conducted according to the body characteristics (e.g. height) and not to the physical performance variables ${ }^{9}$. In fact, previous studies show that height cannot be affected by training ${ }^{16}$ and, considering its positive correlation with maximum jump heights, is also an important requirement for successful performance in those playing positions that require frequent spiking and blocking.

In modern volleyball, teams that dominate the game above the net win most often, and one of the most important requirements is the selection of tall players for playing positions particularly characterized by above the net playing. Similarly to the present study, Nikolaidis et al. ${ }^{8}$ demonstrated that differences in physical characteristics between playing positions in female volleyball players are age-dependent. In this study, no differences were found in the somatotype of the players in different game positions.

For volleyball, which is not a contact sport, huge muscle mass is not necessary for successful performance in any particular position. Being too heavy may even impair repeated jumping performance ${ }^{9}$. Therefore, low to moderate values of the mesomorph somatotype component, especially for the middle blocker position are expected. Given that volleyball is characterized by frequent jumps and fast changes of direction, excess subcutaneous fat tissue is not recommended ${ }^{8,9}$.

In this study, no differences were detected among playing positions for fitness assessment. Similar results were noted by Millic et al. ${ }^{9}$, in which no significant differences were found in the performance of the standing long jump, 20-m sprint, side steps and medicine ball throw tests in young female volleyball players. On the other hand, according to our study, the horizontal jump, shuttle run and 20-m sprint were different among the three age groups, in which these technical-tactical elements are fundamental during the volleyball match.

These abilities enable good performance for the spike and the block, as well as higher contact with the ball above the net ${ }^{17}$. Furthermore, other 
studies ${ }^{8,9,17}$ showed that physical and physiological characteristics between playing positions in female volleyball players are age dependent.

This study presents some limitations: a) The size of the sample was small for each position of the game. In that it is justified by the difficulty to select the athletes for such analyzes of the study due to the long hours of training routines. b) Due to the low sample, there is some attention in transposing the results of this study. Therefore, the external validity of the present study is limited to this population "young female volleyball players". c) Finally, the analysis of the performance of each athlete in their position during the competitions (competitions) could bring additional information on the role of body composition and age in sports performance in young female volleyball players. Yet, this study evaluated female players who compete at the highest level in regional and national tournaments. With experience of 1.0 to 8.0 years of volleyball.

The results of this study indicate that the achievement of the physical tests (horizontal jump, shuttle run and 20-m sprint) is dependent on the age of the players, in which this sample the physical performance was not associated with playing positions. This evidence supports data for future studies in an attempt to understand the influence of body composition and tests of different physical abilities on the evolution of sports performance and its relationship with the chronological and biological development of athletes of different categories of female volleyball base.

This evaluative process may provide a better basis for physical and technical coaches in the progress of female volleyball players. Thus, the development of future studies in this sense are important to support reference values of body composition and results of physical tests, and its relationship with sports performance in female volleyball.

\section{CONCLUSION}

In conclusion, the present study to demonstrated that the height, bone mass and horizontal jump, shuttle run and 20 -m sprint are age dependent, while physical performance independent on the playing positions. It is possible that small sample of each playing position may have interfered in the results. However, this result should be better investigated.

\section{Acknowledgments}

The authors are grateful to the board of directors, technical committee and athletes of the basic categories of Brasília Vôlei, Brazil.

\section{COMPLIANCE WITH ETHICAL STANDARDS}

\section{Funding}

This research did not receive any specific grant from funding agencies in the public, commercial, or not-for-profit sectors. This study was funded by the authors. 


\section{Ethical approval}

Ethical approval was obtained from the local Human Research Ethics Committee - Estácio of Sá University / UNESA / RJ and the protocol (no. 3.199.538) was written in accordance with the standards set by the Declaration of Helsinki.

\section{Conflict of interest statement}

The authors have no conflict of interests to declare.

\section{Author Contributions}

Conceived and designed the experiments: LST, HOC, RVPN and SSA. Performed the experiments: LST and HOC. Analyzed the data: LST, FMC and RFL. Contributed reagents/materials/analysis tools: FMC, RFL, GCTC and GMP. Wrote the paper: LST, HOC, SSA, RVPN, GCTC and GMP.

\section{REFERENCES}

1. Kutáč P, Sigmund M. Assessment of body composition of female volleyball players of various performance levels. J Phys Educ Sport 2017;17(2):556.

2. Palao JM, Manzanares P, Valadés D. Anthropometric, physical, and age differences by the player position and the performance level in volleyball. J Hum Kinet 2014;44(1):223-236.

3. Monteiro Teixeira D, Del Fraro J, Soares F, Reeberg Stanganelli LC, Simões Pires-Neto C, Petroski EL. Características antropométricas em atletas de elite das seleções brasileiras juvenil e adulta de voleibol. Rev Andal Med Deporte 2016;9(4):160-165.

4. Petroski EL, Fraro JD, Fidelix YL, Silva DAS, Pires-Neto CS, Dourado AC, et al. Anthropometric, morphological and somatotype characteristics of athletes of the Brazilian Men's volleyball team: An 11-year descriptive study. Rev Bras Cineantropom Desemp Hum 2013;15(2):184-192.

5. Cosmin SC, Mihaela RA, Claudiu A. Anthropometric characteristics, body composition and physical performance of female cadet volleyball players. J Phys Educ Sport 2016;16(supp.1):664-667.

6. Giannopoulos N, Vagenas G, Noutsos K, Barzouka K, Bergeles N. Somatotype, Level of Competition, and Performance in Attack in Elite Male Volleyball. J Hum Kinet 2017;58:131-140.

7. Martín-Matillas M, Valadés D, Hernández-Hernández E, Olea-Serrano F, Sjostrom M, Delgado-Fernández M, et al. Anthropometric, body composition and somatotype characteristics of elite female volleyball players from the highest Spanish league. J Sports Sci 2014;32(2):137-148.

8. Nikolaidis P, A fonso J, Buśko K, Ingebrigtsen J, Chtourou H, Martin JJ. Positional differences of physical traits and physiological characteristics in female volleyball players-the role of age. Kinesiology 2015;47(1):75-81.

9. Milić M, Grgantov Z, Chamari K, Ardigo LP, Bianco A, Padulo J. Anthropometric and physical characteristics allow differentiation of young female volleyball players according to playing position and level of expertise. Biol Sport 2017;34(1):19-26.

10. Marfell-Jones MJ, Stewart A, De Ridder J. International standards for anthropometric assessment. 2012.

11. Heath BH, Carter JE. A modified somatotype method. Am J Phys Anthropol 1967;27(1):57-74.

12. Wells KF, Dillon EK. The sit and reach-a test of back and leg flexibility. Research Quarterly. Am Assoc Health, Phys Educ Rec 1952;23(1):115-118. 
13. Marques MC, van den Tillaar R, Gabbett TJ, Reis VM, González-Badillo JJ. Physical fitness qualities of professional volleyball players: determination of positional differences. J Strength Cond Res 2009;23(4):1106-1111.

14. Seitz LB, Riviere M, de Villarreal ES, Haff GG. The athletic performance of elite rugby league players is improved after an 8-week small-sided game training intervention. J Strength Cond Res 2014;28(4):971-975.

15. Hegedus EJ, McDonough SM, Bleakley C, Baxter D, Cook CE. Clinician-friendly lower extremity physical performance tests in athletes: a systematic review of measurement properties and correlation with injury. Part 2--the tests for the hip, thigh, foot and ankle including the star excursion balance test. Br J Sports Med 2015;49(10):649-656.

16. Vando S, Filingeri D, Maurino L, Chaabene H, Bianco A, Salernitano G, Foti C, Padulo J. Postural adaptations in preadolescent karate athletes due to a one week karate training cAMP. J Hum Kinet 2013;38:45-52.

17. Paz GA, Gabbett TJ, Maia MF, Santana H, Miranda H, Lima V. Physical performance and positional differences among young female volleyball players. J Sports Med Phys Fitness 2017;57(10):1282-1289.

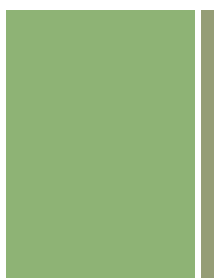

Corresponding author

Henrique de Oliveira Castro

Physical Education Department.

University Center Estácio of Brasília.

CSG 9 14/16 - Taguatinga,

Brasília - DF, Brazil,

Postal code/CEP: 72035-509.

E-mail: henriquecastro88@yahoo.com.br 